\title{
LXIII. A mode of calculating a limit to the direct effect of great eccentricity of the earth's orbit on terrestrial temperatures, showing the inadequacy of the Astronomical theory of Ice Ages and Genial Ages
}

\section{Edward P. Culverwell M.A.}

To cite this article: Edward P. Culverwell M.A. (1894) LXIII. A mode of calculating a limit to the direct effect of great eccentricity of the earth's orbit on terrestrial temperatures, showing the inadequacy of the Astronomical theory of Ice Ages and Genial Ages, Philosophical Magazine Series 5, 38:235, 541-552, DOI: 10.1080/14786449408620670

To link to this article: http://dx.doi.org/10.1080/14786449408620670

\section{Published online: 08 May 2009.}

\section{Submit your article to this journal ๘}

Џ Article views: 2 
Astronomical Theory of 1ce Ages and Genial Ages. 541 An alternative form is got by performing the multiplications and rearranging. It is

$$
\begin{aligned}
& \Sigma A^{2} B^{2} C^{2}-2 \Sigma A^{3} B C-\Sigma A^{3} B C D+4 \Sigma A^{2} B^{2} C-6 \Sigma A^{2} B C D \\
& +\Sigma A^{4}-4 \Sigma A^{3} B+4 \Sigma A^{2} B C+6 \Sigma A^{2} B^{2}-40 A B C D=0 .
\end{aligned}
$$

The symmetry with respect to $\mathrm{A}, \mathrm{B}, \mathrm{C}, \mathrm{D}$ is evident à priori.

Nowbray Hall, near Capetown, S.A.,

September 5, 1894.

LXIII. A Mode of Calculating a Limit to the Direct Effect of Great Eccentricity of the Earth's Orlit on Terrestrial Temperatures, showing the Inadequacy of the Astronomical Theory of Ice Ages and Genial Ages. By Edwand P. Culverwell, M.A., Fellow of Trinity College, Dublin**

THE fundamental assumption made by Dr. James Croll in his well-known writings on the Glacial Periods, and subsequently adopted by Sir Robert $\mathrm{S}$. Ball in 'The Cause of an Ice Age,' is that we may attain to some approximate idea of the lowering of terrestrial temperatures, due to greater winter distance from the sun, by the following considerations :-

Were it not for solar heat the earth would sink to what Ball calls its natural zero, which must be nearly the absolute zero of temperature. Hence the effect of the sun-heat is to maintain it at its present excess above that temperature, and any decrease in sun-heat will be accompanied by a more or less proportionate decrease in the excess of the earth's temperature above the natural zero. To be on the safe side, however, Croll takes this natural zero as a temperature of $-239^{\circ} \mathrm{F}$. (Pouillet's temperature of space), and Ball as $-300^{\circ} \mathrm{F}$. Croll, in chap. xix. of 'Climate and Time,' which he devotes to this subject, supposes the midwinter temperature in an epoch of great eccentricity to be proportional to the sun-heat received on midwinter day-a supposition open to the obvious criticism that the adjustment of temperature to sun-heat can hardly be instantaneous. This is probably the reason why Ball modified the argument and takes the average winter temperature as proportional to the average daily winter heat from equinox to equinox.

I shall show, by actual comparison with terrestrial temperatures, that this assumption of the proportion between the

* Communicated by the Author. 


\section{Mr. E. P. Culverwell on the Inadequacy of the}

temperature at a place and the sun-heat received is utterly wide of the mark; but first I will endeavour to trace the origin of Croll's mistake. In 1830 Herschel wrote a paper "On the Astronomical causes which may influence Geological Phenomena," and in it he dealt with the possible changes of terrestrial temperature due to clianges in the earth's minor axis, making use of the argument that a small percentage alteration above the absolute zero (which he says some place at $-1000^{\circ} \mathrm{F}$, some at $-5000^{\circ} \mathrm{F}$., and some lower still) due to a small percentage change in the annual quantity of sun-heat received would produce all the great change in temperature required by geologists. In such a case the method is perfectly valid, except that terrestrial radiation should not be taken as simply proportional to absolute temperature. In the centuries during which the earth receives less annual heat from the sun we may fairly suppose that a practically permanent state is reached in which the heat annually received by the globe as a whole is equal to that radiated by the globe as a whole. In that case we cannot complain of Herschel in 1830 treating the radiation as proportional to the temperature, and then treating the percentage decrease in temperature of the globe as a whole as equal to the percentage decrease in sun-heat received. $\mathrm{Had}$ he taken the law of cooling as at present stated-i.e. radiation varies as the fourth power of absolute temperature-the percentage decrease in temperature would (for small changes) only be one fourth of the percentage decrease in heat received. Subsequently, Herschel, in a rather confused paragraph in his ' Outlines,' $369 a$, referred to by Croll (p. 37) as his authority, appears to apply the same method to calculating temperature differences between the northern and southern hemispheres in the period of great eccentricity. But he rejects the calculation immediately after on the ground that loss of heat in winter, through greater distance from the sun, is compensated for by greater duration of wiuter. Hence the paragraph does not really seem to justify Croll's application. For Croll applies the method to the temperature of limited portions of the earth's surface, in which, owing to the fact that heat is continually being transferred from one region to another, there is never a time at which the gain by sun-heat is equal to the loss by radiation.

The statement just made shows that for Croll's argument to have any practical volidity as a method of calculating the winter temperatures in the epoch of great eccentricity, it is necessary not only that the temperature adjustments shall be made with great rapidity but also that the direct effect of 
sun-heat on terrestrial temperatures in the latitudes with which glaciation is concerned shall be great compared with that of the heat transferred from latitude to latitude by air and ocean currents. That this is not the case in regard to the changes of temperature from summer to winter, we have a ready means of showing ; indeed it appears that the direct effect of winter sun-heat in northern latitudes is but a trifling factor in keeping the temperature above the "natural zero" when compared with the heat transferred from place to place. For consider the equator: it receives nearly the same daily sunheat during winter and summer, and its temperature stands continuously about $380^{\circ} \mathrm{F}$.above Ball's "natural zero." Hence, if we calculate and then plot on a diagram the average daily summer and winter sun-heats for each latitude, on such a scale that the equatorial sun-heat is represented by 380 , then the ordinates giving the summer and winter sun-heats for the different latitudes should also, if Herschel's principle were applicable, give the summer and winter excesses of their temperatures above the natural zero. In fig. 1 this has been done for latitudes $40^{\circ}$ to $90^{\circ}$, the only ones we are concerned with in dealing with the Glacial Period. I have also shown by the dotted lines the mean of the 'Challenger's' January and July temperatures for the meridians $90^{\circ} \mathbf{E}$. and $90^{\circ} \mathrm{W}$. passing through the middle of the great Asiatic and American continents up to latitude $70^{\circ}$, beyond which reliable information cannot be obtained. The scale of sun-heat is shown at the left side, and the scale of Fahrenbeit temperatures at the right of the centre line. By examining the figure we see that even in the Continental areas, where the most extreme variations are observed, the midwinter temperatures bear no relation whatever to the very small amount of winter sun-heat; so that we infer that the transference of heat from one latitude to another is the chief factor in winter temperatures.

It we were to follow Croll's method, and take the midsummer and midwinter sun-heats instead of the daily average, the discrepancy shown in the figure between actual temperatures and sun-heats would be enormously increased.

To complete the criticism, let us examine the most extreme of all climates, that of Yakutsh in Siberia. Here the midsummer temperature rises to about $370^{\circ}$ over the "natural zero" and the midwinter sinks to $260^{\circ}$. But the daily average sun-heat in summer is to the daily average in winter as 1300 is to 260 , or as 370 is to 74 . Hence if the midwinter temperature be right, the midsummer ought to be $1000^{\circ} \mathrm{F}$, or if the midsummer be right, the midwinter ought 
544 Mr. E. P. Culverwell on the Inadequacy of the

to be $-226^{\circ} \mathrm{F}$. If, following Croll's method, we calculate the midsummer and midwinter sun-heats, we find the ratio to be 7600 to 260 , or 370 to $12 \cdot 5$. It is unnecessary to dwell on the discrepancy between these figures and the temperatures.

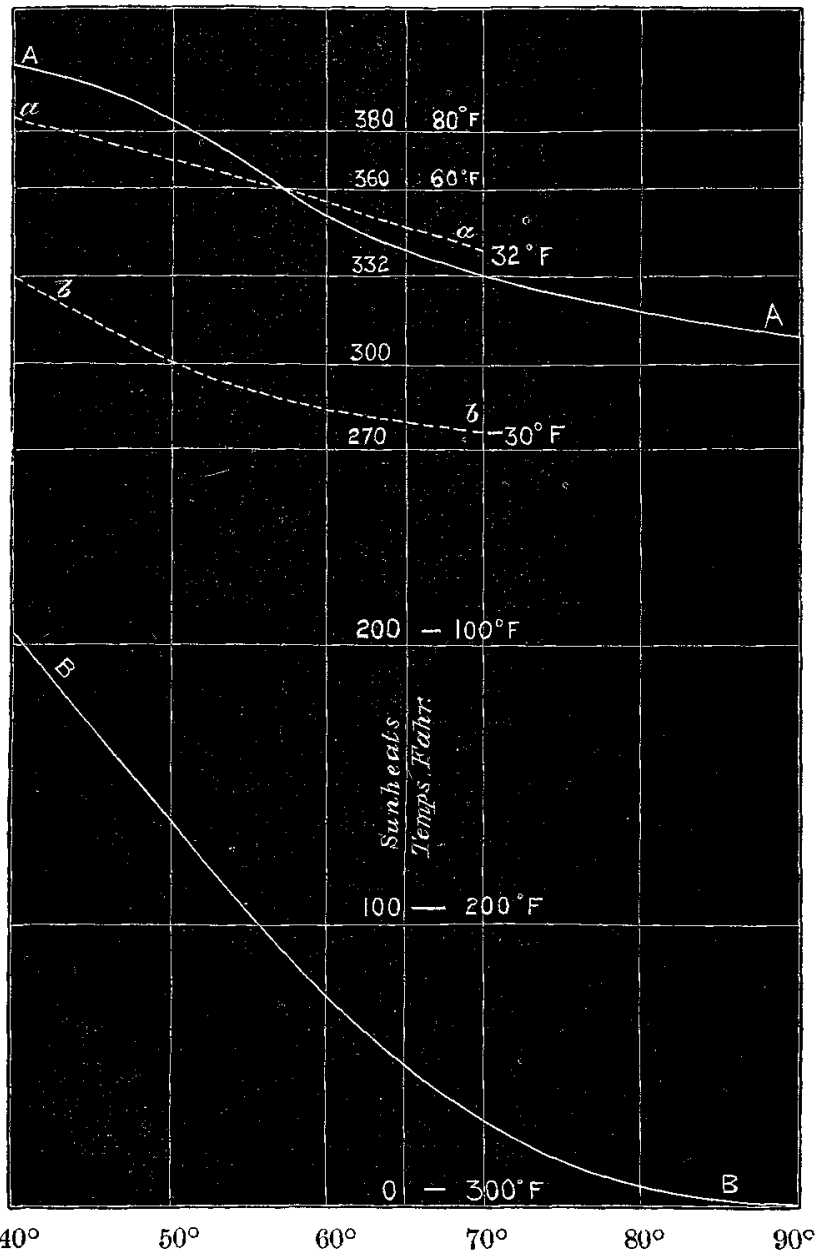

1ig. 1.-Showing the want of proportionality between winter temperatures and winter sun-heat.

A A, curve of average daily summer sun-heat. $B B$, curve of average daily winter sun-heat. a a, curve of mean Continental July temperatures. $b b$, curve of mean Contimental January temperatures. 
When, therefore, there is such a complete absence of proportion between the summer and winter temperatures and the summer and winter sun-heats, what ground can be assigned for the assumption of a rough proportion between the changes in the summer or winter temperatures and the changes in the corresponding sum-heats due to eccentricity? Even if the temperatures themselves did show a certain rough proportion to the sun heats, we could not expect as near an approach to the proportion in their changes, because the disturbing element might be large compared to the changes in the temperatures, though small compared to the temperatures themselves. $A_{s}$ it is, the argument breaks down completely; and the assumption on which the supporters of the Astronomical theory of the Ice Ages and Genial Ages rely is found to be nothing but a vague speculation, not only unsupported by the physical evidence bearing on the subject, but in direct opposition to it. The weakness of the foundation, however, las not deterred the astronomical geologists from erecting on it an edifice of vast proportions. They affirm that there have been a number of successive glaciations, alternating with genial ages at intervals of about 10,500 years, that glaciation must have been simultaneous all round the pole, that a glacial age in the nortbern hemisphere must have been accompanied by a genial one in the southern, and vice versâ. And as M. Leverrier's calculations show that the last period of considerable eccentricity was abont 100,000 years ago, the last Ice Age must have occurred about that date. Dr. Croll indeed fixes all the possible dates for three million years of past and one million of future time; but Sir Robert Ball declines to fix the dates, not from any want of implicit confidence in the theory, but merely from a probable want of accuracy in the determination of the astronomical constants involved. I imagine, however, that Sir Robert Ball would accept as fairly reliable Leverrier's calculations for this comparatively short period, though he does not accept those of Croll for the longer period. Hence we may safely assume with Croll, that the last Ice Age must have terminated 80,000 years ago, if his theory be correct.

When Croll's theory was originally published, the general opinion of geologists was that the date of the Ice Age as fixed by the theory was far too recent. But the uniformitarian school of those days has now been replaced by the modern school, which, relying on calculations of the rate of denudation, tends to fix the glaciation of North America as hardly more than ten or twenty thousand years ago. Hence geologists are now disposed to welcome any criticism of 
Croll's hypothesis which tends to leave more freedom to the somewhat fluctuating demands of their science.

Is there, then, any physical method of estimating the changes in midwinter temperature due to eccentricity? The problem is of course far too complicated to be rigorously solved; but happily, in respect of the direct effect of sunheat, we have what seems a fair and rational method of calculation. When, in the long winter of the supposed glacial epoch, the earth was much farther from the sun than at present, each parallel of latitude of course received less daily winter heat than the same parallel now receives. But let us find what parallels of latitude now receive the same sun-heat in winter as the parallels $40^{\circ}, 50^{\circ}, 60^{\circ}, 70^{\circ}, 80^{\circ}$, and the pole, $90^{\circ}$, which I will call the standard parallels, received in the long winter of great eccentricity. I take three bases of comparison-

Irirst, following Croll's method, I find that latitudes $43^{\circ}$, $52^{\circ}, 61^{\circ}, 70^{\circ}, 80^{\circ}$, and $90^{\circ}$ receive on midwinter day at present the same sum-heat as the standard latitudes received on their midwinter day in the period of great eccentricity.

Now as to the temperatures. I think it is evident that the present midwinter temperatures of $43^{\circ}, 52^{\circ}$, \&c. must, so far as direct sun-heat is concerned, be somewhat higher than those of the standard latitudes in the former epoch. For though the midwinter sun-heat is the same, the standard latitudes have had a longer period of cooling, i. e. the radiation from them in the earlier epoch has exceeded the sun-heat received for a few days longer than in the case of latitudes $43^{\circ}, 52^{\circ}$, \&c. at present.

Second. I find that latitudes $43^{\circ} \cdot 3,52^{\circ} \cdot 4,61^{\circ} \cdot 7,71^{\circ} \cdot 3$, $81^{\circ}$, and $90^{\circ}$ nov receive in their winter of 179 days just the same daily average of sun-heat as the standard latitudes received in their supposed glacial winter of 199 days.

In this case, though the period over which the daily supply is taken is shorter in the case of $43^{\circ} \cdot 3,52^{\circ} \cdot 4$, \&c. than for the standard latitudes, yet the former receive appreciably more midwinter sun-heat than the latter; so that whatever difference of temperature there is due to the first cause will be more or less counterbalanced by the other, and we are probably not far wrong in saying that, so far as direct sun-heat is concerned, the present midwinter temperatures of latitudes $43^{\circ} \cdot 3$, $52^{\circ} \cdot 4,61^{\circ} \cdot 7,71^{\circ} \cdot 3,81^{\circ}$, and $90^{\circ}$ must be about the same as those of $40^{\circ}, 50^{\circ}, 60^{\circ}, 70^{\circ}, 80^{\circ}$, and $90^{\circ}$ were in the epoch of great eccentricity.

Third. I find that latitudes $44^{\circ} \cdot 2,54^{\circ}, 63^{\circ} .5,74^{\circ}$, and $84^{\circ} .5$ now receice the same totul sun-leeat in the 199 coldest days 
of our year as the corresponding standard latitudes received in the 199 coldest days of their year in the epoch of great eccentricity, that is, of course, in their winter (of course $90^{\circ}$ cannot be brought into this comparison). In other words, the same daily average of sun-heat is received during the 199 days by the corresponding latitudes in the present and former epuchs.

But it is quite evident that the present mid winter temperatures of $44^{\circ} \cdot 2,54^{\circ}$, \&c. must, so far as the direct effect of sun-heat is concerned, be lower than the midwinter temperatures of the standard latitudes in the epoch of great eccentricity. For if the actual daily sun-heat received by latitude $44^{\circ} \cdot 2$ at present were the same for each of the 199 days as that received on the corresponding dav by latitude $40^{\circ}$ in the former epoch, then we could affirm that, so far as sun-heat alone was concerned, the temperatures of the two latitudes ought to be equal. But since $44^{\circ} \cdot 2$ receives far more than this amount of daily heat in the beginning of the 199 days, its temperature will be higher at first, and therefore, since the total heat received up to midwinter is the same in both cases, the temperature of the $44^{\circ} \cdot 2$ must be lower at midwinter-otherwise it would be higher all the time, which is impossible. For if it were higher all the time, it would be constantly losing more heat by radiation; wherefore, as it only receives the same quantity of heat, its final temperature must be lower, not higher. Thus the supposition that the midwinter temperature of $44^{\circ} \cdot 2$, so far as direct sun-heat is concerned, is higher than that of $40^{\circ}$ in the epoch of great eccentricity, involves an absurdity.

So far I have only dealt with the effect of the winter sunheat. Consider now the annual sun-heat. First, the present summer sun-heat on lat. $44^{\circ} .2$ in the remaining 166 days of our year is far less ( 9 per cent. less) than the sun-heat received by lat. $40^{\circ}$ in its summer of 166 days in the period of great eccentricity. Hence, so far as summer sun-heat is concerned, latitude $44^{\circ} \cdot 2$ now begins its 199 days at an appreciably lower temperature than $40^{\circ}$ began its 199 days in the former epoch, and therefore, on this account as well, its present midwinter temperature should be lower than the midwinter temperature of $40^{\circ}$ was in the suppused glacial winter.

Of course all the foregoing applies equally to the other latitudes.

Hence we conclude that, other things equal, the direct effect of the altered sun-heat in the epoch of great eccentricity was probably to place latitudes $40^{\circ}, 50^{\circ}, 60^{\circ}, 70^{\circ}$, and $80^{\circ}$ in about the same conditions as to midwinter temperature as $43^{\circ} \cdot \ddot{y}, 52^{\circ} \cdot 4,61^{\mathrm{c}} \cdot 7,71^{\circ} \cdot 3$, and $81^{\circ}$ are at present, and that 
certainly the effect was not to lower their midwinter temperuture to those of $44^{\circ} \cdot 20,54^{\circ}, 63^{\circ} \cdot 5,74^{\circ}$, and $84^{\circ} \cdot 5$, at the present time.

Next as to the transference of heat. Consider the latitudes from Cornwall to the Shetland Isles, i. e. $50^{\circ}$ to $60^{\circ}$. In all probability the daily winter transference of equatorial heat to latitude $50^{\circ}$ in the period of great eccentricity was greater than that to latitude $54^{\circ}$ at present. For there is no doubt that the greater proportion of the transference is due to ocean currents. Now the experiments of the Prince of Monaco on the rate of motion of the Gulf Stream show that between the Azores and Ireland, and between Ireland and Norway, it is about 3.9 miles per day, or say 10 degrees in the half year. Hence the winter leating of the British Isles by means of the Gulf Strean must depend very largely on the daily summer heat at a point about 10 degrees off on the pailh of the Gulf Streum, and this was much greater during the period of greatest eccentricity than now. For it is ensy to see by an examination of fig. 2 that during the 166 days of that short summer, latitude $50^{\circ}$ received more heat than is now received in an equal time by any latitude, even in the tropics, while $60^{\circ}$ received as much as $52^{\circ}$ now receives, $70^{\circ}$ as much as $59^{\circ}$, and $80^{\circ}$ as much as $66^{\circ}$ now receives. Thus when we remember how important a factor in winter temperature the heat transferred by ocean currents is, it might be plausibly maintained that the winter temperatures of the higher latitudes were probably higher in the supposed Glacial epoch than they are at present. But as the data are insufficient for obtaining a quantitative result by such arguments, it is better to be content with the extreme temperature limit, as fixed by the third method. This is obtained as follows :-

As we go northwards from latitude $50^{\circ}$ to latitude $70^{\circ}$ along the meridian of Greenwich we get a fall of $15^{\circ} \mathrm{Fahr}$. in the midwinter temperature. Hence in that longitude the midwinter temperatures of latitudes $54^{\circ}, 63^{\circ} .5$, and $74^{\circ}$ are about $3^{\circ} \mathrm{Fahr}$. lower than those of $50^{\circ}, 60^{\circ}$, and $70^{\circ}$. Hence the fall of temperature in the epoch of greatest eccentricity cannot have been as much as $3^{\circ} \mathrm{Fahr}$. in Great Britain, so far as the direct effect of sun-heat is concerned.

In mid-America and mid-Asia the change is somewhat greater. Taking the mean as we go northward from lat. $50^{\circ}$ to lat. $70^{\circ}$ along the meridians $90^{\circ} \mathrm{W}$. long. and $90^{\circ} \mathrm{E}$. long., we find that the midwinter temperature falls by $1 \frac{1}{4}^{\circ} \mathrm{Fahr}$. for each degree of latitude passed over to the northward. This would give a lowering of midwinter temperature of about $5^{\circ}$ Fahr. for the 4 degrees of latitude by which the isothermals are shifted in the epoch of greatest eccentricity. 
Astronomical Theory of Ice Ages and Genial Ages. 549

If, instead of taking the epoch of greatest eccentricity, we take the epoch of considerable eccentricity which occurred about 100,000 years ago, as calculated by Leverrier, we must take off about one fourth part from the above results.

Since the whole of Croll's theory of the stoppage of the Gulf Stream depends on a previous vast cooling of the northern hemisphere (accompanied by a heating of the southern hemisphere), it is evident that, unless the temperature results here given be utterly erroneous, they dispose once and for all of the Astronomical theory of the Ice Age. I have, however, prepared a further examination of that theory for the 'Geological Magazine' of January 1895.

With regard to the Genial Age, the insignificance of the changes effected by the astronomical cause is still more remarkable. When the eccentricity is at its maximum, and the winter occurs in perihelion, it will be seen from the figure that the winter isothermals are shifted $2 \frac{1}{2}$ or 3 degrees to the north and the summer ones about 5 degrees to the south. For instance, in our coldest 166 days lat. $57^{\circ} .5$ receives just the same sun-heat as lat. $60^{\circ}$ in the 166 days of the "genial" winter. To dwell on the inadequacy of this as the cause of the prevalence of tropical vegetation in Greenland and Spitzbergen would be mere loss of time. But Croll has an additional cause to account for a really Genial Age at the pole, namely, increased obliquity of the ecliptic. The maximum effect of this would be to increase by about 1 part the summer sun-heat received at the Poles. Hence, having said that $\frac{1}{18}$ more ice would be melted annually at the Poles than at present, Croll proceeds to state that "the effects of eccentricity and obliquity thus combined " $[i . e$., the maximum obliquity synchronizing with the "genial " conditions of the orbit] "would probably completely remove the polar ice-cap from off the latter hemisphere [that enjoying the "genial" conditions] and forest trees might then grow at the Pole."'Climate and Time,' 2nd edition, pp. 402-403. It is as easy to make such assertions as this as it is difficult to alduce any shadow of a reason in support of them. That Croll should have been the person to make the astounding statement that the addition of $\frac{1}{18}$ part of the summer heat at the Poles would prevent ice forming there during the winter is the more extraordinary, because in order to get over the difficulty that the summer heat in the supposed glacial epoch was just as much increased as the winter heat was diminished, it was necessary for him, throughout the earlier portion of his book. to insist on the absolute inefficiency of summer heat to melt ice and snow or to mitigate the effects of winter cold (see pp. 58-66 and p. 324 of 'Climate and Time'). So far, then, as 
this suggestion of an additional cause of the Genial Age may require an answer, I leave Dr. Croll's earlier pages to answer his later ones.

The mode in which the calculations were made must now be explained. Originally I had intended to evaluate the integrals which give the winter sun-heat on each latitude, but the calculations appeared so long that I thought of using a graphic method by photographing a terrestrial globe in various positions. But having met with Mr. Meech's paper in vol.ix. of the 'Smithsonian Contributions to Knowledge,' I used his values for the daily heat on each 15th day of the year for intervals of 10 degrees of latitude as sufficiently close approximations to the quantities of sun-heat received on that day and the seven preceding and succeeding days, nxcept in a few cases where the rate of change varied considerably, when I used a graphic method of interpolation by plotting the curve on millimetre-paper. Thus I was able to get the total quantity of sun-heat received $(a)$ for winter and summer, using the words in their technical sense of the intervals between the equinoxes; $(b)$ for our coldest 199 days; and (c) for our coldest $166^{\circ}$ days, these being the lengths of the supposed glacial and genial winters. Of course, since the total anual sun-heat on any latitude is independent of the length of the seasons, it was easy to get the summer sun-heats for our $166^{\circ}$ and 199 hottest days from these figures.

For the purposes of this paper I reduced the numerical values I had obtained from Mr. Meech's tables, so that the quantity of winter or summer sun-heat falling on the equator should be represented by 380 , that being the excess of temperature of the equator above Ball's "natural zero." The numbers thus obtained are :-

$\begin{array}{rrrrrrr}\text { Latitudes.................... } & 40^{\circ} & 50^{\circ} & 60^{\circ} & 70^{\circ} & 80^{\circ} & 90^{\circ} \\ \text { Summer sun-heat ........... } & 399 & 379 & 347 & 329 & 317 & 306 \\ \text { Winter sun-beat . .......... } & 199 & 138 & 79 & 32 & 7 & 0 \\ \text { " coldest } 199 \text { days ... } & 229 & 161 & 101 & 48 & 16 & 5 \\ \text { " coldest } 166 \text { days ... } & 179 & 121 & 66 & 23 & 3 & 0\end{array}$

I have plotted these numbers to scale in fig. 2 .

The "summer" and "winter" sun-heats are of course the same whatever be the relative lengths of those seasons. Hence the shift of the isothermals is shown by lengths of the intercepts made by the sun-heat curves in fig. 2 on a horizontal line. The actual amount of the shift of the winter isothermals in the supposed Glacial epoch, as obtained from this figure, is, $40^{\circ}$ to $44^{\circ} \cdot 2,50^{\circ}$ to $54^{\circ}, 60^{\circ}$ to $63^{\circ} \cdot 5,70^{\circ}$ to $74^{\circ}$, and $80^{\circ}$ to 
Astronomical Theory of Ice Ages and Genial Ages. 551 $84^{\circ} \cdot 5$. These are practically identical with the result of the larger figure I originally made.

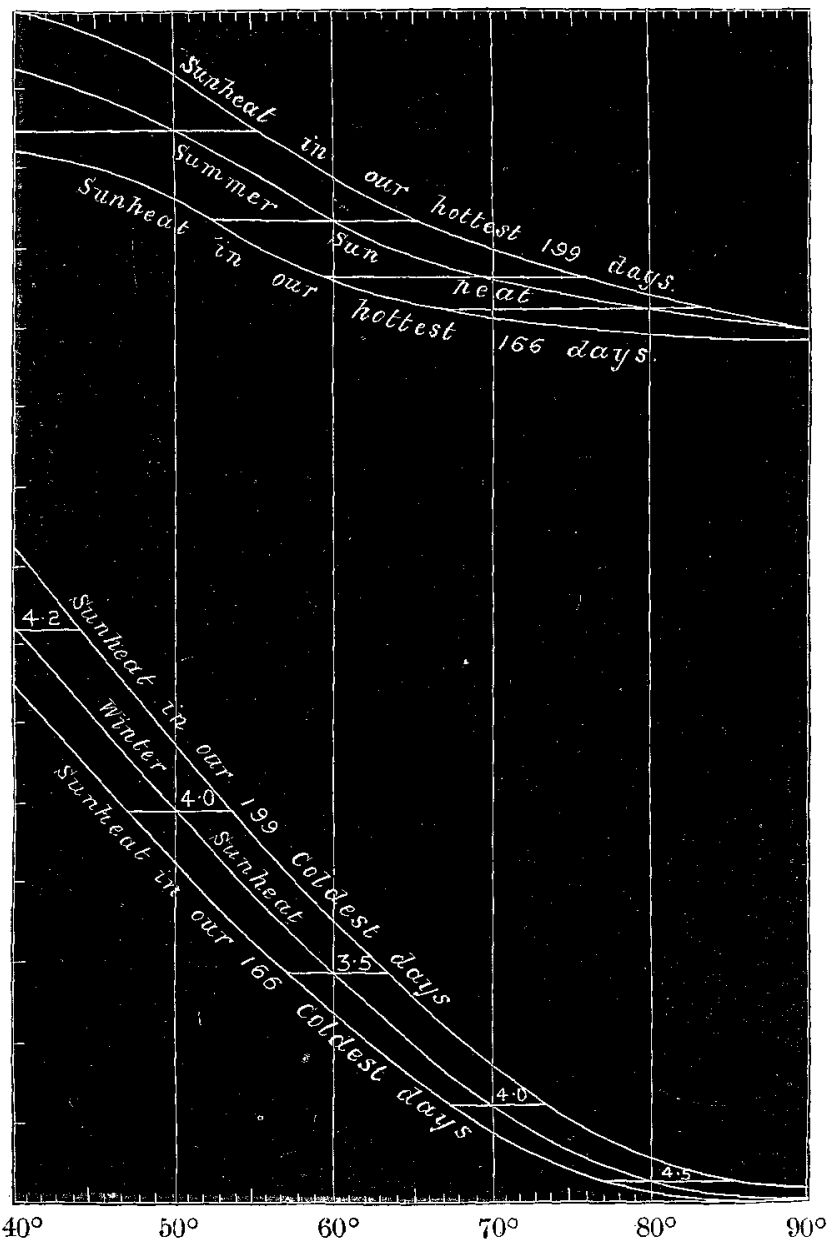

Fig. 2.-Showing the shift of the isothermals in the epoch of great eccentricity, as calculated by the thixd method.

There is one, and, as far as I can see, only one, objection that can be made to the results I have obtained. It might be urged that the winter heat at present received by lat. $54^{\circ}$ from ocean currents is much in excess of that received in the epoch of great eccentricity by lat. $50^{\circ}$, and that therefore lat. $54^{\circ}$ at present may be much warmer than lat. $50^{\circ}$ was in the earlier epoch. The observations already made on 
ocean currents seem a sufficient answer, but happily the objection can be entirely disposed of. For the transference of heat from ocean currents to lat. $54^{\circ}$ at present depends on the excess of temperature of the ocean over what I may call the sun-heat temperature of $54^{\circ}$. Hence the objection supposes that the present midwinter excess of ocean temperature at $54^{\circ}$ over the sun-heat temperature at $54^{\circ}$ is greater than the excess of ocean temperature at $50^{\circ}$ over the sun-heat temperature at $50^{\circ}$ was in the epoch of great eccentricity. But since the present midwinter sun-heat temperature at $54^{\circ}$ is the same as that at $50^{\circ}$ in the earlier epoch, this supposition requires the midwinter ocean temperature to be now higher at lat. $54^{\circ}$ than it was at lat. $50^{\circ}$ in the epoch of great eccentricity. But since the sun-heat temperature of the ocean at lat. $50^{\circ}$ at the earlier epoch was the same as that at lat. $54^{\circ}$ now, there is nothing which could tend to make the winter temperature of the ocean at $50^{\circ}$ in the earlier epoch lower than that at $54^{\circ}$ now, while the far greater summer heating the water then underwent in the lower latitudes must have made its winter temperature higher than it is now. Hence the supposition that the winter temperature of the ocean would be lower is disposed of for Great Britain at least*.

Of course the foregoing argument proceeds on the supposition that the configuration of the land, and with it the general character of the ocean currents and air currents was the same at the epoch of great eccentricity as it is now. It then supplies a satisfactory proof that there is nothing in the astronomical causes which would alter those currents, or at least nothing of the nature required by Croll's theory.

If, instead of taking the radiation proportional to the absolute temperature, we take Stefan's law, published in 1881, giving it as proportional to the 4 th power of the temperature, we should reduce Croll's result by one fourth. Thus his $45^{\circ} \cdot 3 \mathrm{~F}$. would come down to $11^{\circ} \mathrm{F}$.; and if we further consider that ocean and air currents are twice as effective as winter sun-heat in maintaining the temperature we should get a lowering of about $4^{\circ} \mathrm{F}$. at midwinter, about the same as the amount $I$ arrive at otherwise. This is not quite accurate, for we ought to take the 4th power from zero, not from -239 , and also we ought to take the percentage diminution, not of the solar heat, but of the total heat. Still the calculation may belp in a rough way to show the reasonableness of the results obtained in the paper.

* Of course in strict accuracy we should use in the argument not $54^{\circ}$ but the somewhat lower latitude whose midwinter sun-heat temperature at present is the same as that of $50^{\circ}$ in the period of great eccentricity. 